NASA Technical Memorandum 107481

ASME-97-GT-308

\title{
Combustion Noise at Elevated Pressures in a Liquid-Fueled Premixed Combustor
}

Douglas Darling

Lewis Research Center

Cleveland, Ohio

Krishnan Radhakrishnan

NYMA, Inc.

Brook Park, Ohio

Ayo Oyediran

AYT Corporation

Brook Park, Ohio

Prepared for the Turbo-Expo 97

sponsored by the International Gas Turbine Institute of the American Society of Mechanical Engineers

Orlando, Florida, June 2-5, 1997

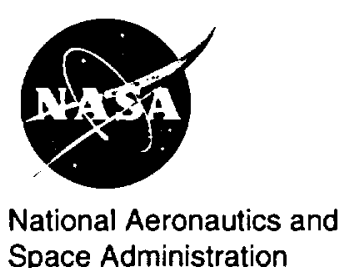

Space Administration 


\section{COMBUSTION NOISE AT ELEVATED PRESSURES IN A LIQUID-FUELED PREMIXED COMBUSTOR}

\author{
Douglas Darling1 \\ Westinghouse Electric Corporation \\ Orlando, FL
}

\author{
Krishnan Radhakrishnan \\ NYMA, NASA Lewis Research Center \\ Brook Park, OH
}

\author{
Ayo Oyediran \\ AYT Corp. \\ Brook Park, $\mathrm{OH}$
}

\begin{abstract}
Noise generated in gas turbine combustors can exist in several forms-broadband noise, sharp resonant peaks, and regular or intermittent nonlinear pulsing. In the present study, dynamic pressure measurements were made in several JP-5-fueled combustor configurations, at various mean pressures and temperatures. The fluctuating pressure was measured at mean pressures from 6 to $14 \mathrm{~atm}$ and inlet temperatures from $550 \mathrm{~K}$ to $850 \mathrm{~K}$. The goal of the present work was to study the effect of changes in mean flow conditions on combustor noise: both broadband noise and sharp tones were considered. In general, the shape of the broadband noise spectrum was consistent from one configuration to another. The shape of the spectrum was influenced by the acoustic filtering of the combustion zone. This filtering ensured the basic consistency of the spectra. In general, the trends in broadband noise observed at low mean pressures were also seen at high mean pressures; that is, the total sound level decreased with both increasing equivalence ratio and increasing inlet temperature. The combustor configurations without a central pilot experienced higher broadband noise levels and were more susceptible to narrow peak resonances than configurations with a central pilot. The sharp peaks were more sensitive to the mean flow than was the broadband noise, and the effects were not always the same. In some situations, increasing the equivalence ratio made the sharp peaks grow, while at other conditions, increasing the equivalence ratio made the sharp peaks shrink. Thus, it was difficult to predict when resonances would occur; however, they were reproducible. Acoustic coupling between the upstream and downstream regions of the combustor may play a role in the sharp-peaked oscillations. Noise was also observed near lean blow out. As with other types of noise, lean blow out noise was affected by the combustion chamber acoustics, which apparently maintains the fluctuations at a uniform frequency. However, the actual conditions when this type of noise was experienced appeared to simply
\end{abstract}

follow the lean blow out limit as it varied with mean temperature and pressure.

\section{INTRODUCTION}

Noise generated in gas turbine combustors can exist in several forms-broadband noise, sharp resonant peaks, and regular or intermittent nonlinear pulsing. Broadband combustion noise, which can occur in open or confined flames, is characterized by a wide peak in its spectrum. The unsteady heat release rate that causes this noise can be attributed to the turbulence of the flame structure or incoming air flow (Strahle, 1972). In confined flames the heat release from the combustion may couple with the acoustics of the combustion chamber. If this feedback has the appropriate phase and there is little damping and losses at the boundaries, an instability is seen. Sometimes, this feedback is designed into a combustor to improve performance, as in the case of pulse combustors (Putnam, et al., 1986). Finally, noise can be associated with approaching the lean blow out limit of the combustor. This particular noise becomes quite loud close to lean blow out, and appears highly nonlinear when there is periodic extinction and reignition of the flame.

Because unsteady heat release rate is the source of combustor noise, mechanisms responsible for this unsteadiness must be identified. Unsteady heat release rates arise due to many factors (Mahan, 1984). For example, the turbulence of the incoming air can be amplified by the flame. In some cases small scale turbulence in the flame itself gives rise to unsteady heat release rates. Alternatively, large scale structures can cause the heat release rate to become unsteady (Keller, et al., 1982). Perturbations in chemical kinetic rates, due to temperature, pressure, and concentration fluctuations, can also be a factor (Darling, et al., 1995). The fuel flow rate can be unsteady, resulting in the unsteady flow of reactants into the flame zone, thus causing the heat release rate to fluctuate. In fact, perturbing the fuel flow rate is being considered as a means of actively reducing

\footnotetext{
1 The experiments were performed while formerly employed at the NASA Lewis Research Center, Cleveland.
} 
combustor noise (Richards, et al., 1995 \& Neumei et al., 1996). For liquid-fueled combustors, perturbations in atomization and rate of vaporization can also result in the unsteady introduction of fuel into the flame zone (Heidmann and Groeneweg, 1969, \& Heidmann and Weiber, 1966).

These modes of unsteady heat release rate may or may not couple with the acoustics of the combustion chamber. If it does couple with the chamber acoustics, the unsteady heat release rate may or may not be in the appropriate phase to amplify the pressure fluctuations. If there is the correct phase relationship, the boundary conditions are important, because they determine if an instability will develop. The acoustic boundary conditions of a combustor are a function of the geometry of the system and the velocity and thermodynamic properties of the flow through the boundary. In addition to reflecting and transmitting acoustic waves, the boundary may contribute directly to the interaction between the acoustics and the heat release rate, as when entropy waves are transformed into acoustic disturbances at the exit of a combustion chamber (Keller, 1995).

Premixed combustors are being considered for advanced aircraft gas turbines, because their potential for low $\mathrm{NO}_{\mathbf{x}}$ (oxides of nitrogen) emissions has been demonstrated in ground-based applications. However, these combustors are especially susceptible to instabilities caused by interactions between the acoustics and the fluctuating heat release rate. Resonance occurs when the fluctuating heat release rate is in phase with the fluctuating pressure, along with insufficient damping and/or transmission at the boundaries. If the resonance is linearly unstable, it will grow until it reaches a limit cycle. Instabilities can cause mechanical failure, as well as increased heat transfer and environmental noise. Meanwhile, broadband noise occurs in premixed combustors even when there is no discernible resonance. Thus, understanding and controlling noise are necessary for the successful application of premixed combustors.

Premixed combustors are susceptible to fluctuations in the heat release rate caused by the factors listed above: hydrodynamic instabilities (e.g., vortex shedding); variations in chemical kinetic rates; turbulence of the incoming air stream; fluctuations in the rate at which fuel is delivered to the flame; perturbations in the atomization and rate of vaporization of the liquid fuel; and perturbations in fuel-air mixing. Due to the complexity of the situation, it is not often easy to predict the dominant physics for noise production in a real combustor. Specific combustors invariably need to be tested, and retested when design modifications are made.

This paper describes results of experimental measurements of combustor noise made at various operating conditions. Combustor tests in continuous-flow combustors are often performed at atmospheric, medium, and high pressures. Frequently, such studies involve use of different test facilities, with different acoustic boundary conditions and perturbations in the air supplies. Therefore, it is often difficult to separate the effects of mean flow conditions and combustor performance from those due to variations in test facilities. There is also concern as to whether the same type of noise would be excited at elevated pressure as at low pressure. In this study, dynamic pressure measurements were made in several combustor configurations at various mean pressures and temperatures, using the same test facility. The goal of the present work was to study the effect of changes in mean flow conditions on combustor noise; both broadband noise and sharp tones were considered.

\section{EXPERIMENTAL SETUP}

The dynamic pressure measurements were made in the Engine Research Building at NASA Lewis Research Center. The facility was developed to test model combustors at elevated temperatures and pressures. The experimental setup is shown in figure 1 . The liquid fuel (JP-5) and air were introduced into the combustor in three stages. Just downstream of the dump plane (i.e., fuel-air mixture inlet plane) the flow area was $0.050 \mathrm{~m}^{2}$. Over a distance of $0.14 \mathrm{~m}$ from the dump plane, the duct had converged to an area of $0.022 \mathrm{~m}^{2}$. The flame tube had a cross section of $0.22 \mathrm{~m} \times 0.10 \mathrm{~m}\left(0.022 \mathrm{~m}^{2}\right)$. A quartz window, installed between the dump plane and the end of the converging section, allowed visual observation of the flame. At a total distance of $0.94 \mathrm{~m}$ from the dump plane, the flow exhausted into a chamber, where water sprays cooled the combustion products.

Four different combustor configurations are considered in this paper, as shown on Table I. In this table, the numbers 1 and 2 following "premixed" and "pilot" refer to the different relative axial positions of the stages. For all results presented in this paper the fuel-air ratios for all three stages were equivalent for a given operating condition. The equivalence ratio $(\Phi)$ varied from 0.35 to 0.57 . The mean pressure $(p)$ varied between $6 \mathrm{~atm}$ and $14 \mathrm{~atm}$, and the inlet air temperature $\left(T_{\text {in }}\right)$ was in the range $550 \mathrm{~K}$ to $850 \mathrm{~K}$. The Mach number downstream of the flame was typically about 0.07 .

The fluctuating pressure measurements were made with a piezoresistive pressure transducer, installed in the flame tube (i.e., in the $0.022 \mathrm{~m}^{2}$ section of the apparatus). The transducer was attached to a semi-infinite tube, to prevent the tube acoustics from interfering with the measured signal. The power density spectra presented in the following sections represent a linear average of 150 spectra. Frequently, however, a larger number of samples was taken to ensure adequacy of the use of 150 samples.

\section{BROADBAND NOISE RESULTS}

Three basic types of noise were observed in the premixed combustor: broadband noise, narrow peak acoustic tones, and pulsing oscillations associated with flame instability near lean blow out. Often, during our studies, the combustor did not exhibit any resonance. Figure 2 shows a typical power spectral density in the absence of resonance. This spectrum was taken in configuration 3 and operating conditions as follows: mean pressure of $10 \mathrm{~atm}$, equivalence ratio of 0.52 , and a flame temperature of $1840 \mathrm{~K}$. In this case the total pressure fluctuation (i.e. over all frequencies) was $1.92 \mathrm{kPa}$ (rms), compared with $0.47 \mathrm{kPa}$ (rms) when air alone was flowing through the combustor (i.e., there was no flame). Although the actual amplitudes and frequencies varied with the operating conditions, the basic shapes of the spectra were consistent from one point to another and even from one configuration to another. 
The peaks and valleys in the noise spectrum were probably due to the broadband turbulent noise generated by the flame being filtered by the acoustics of the combustion chamber. An acoustic analysis of the flame tube shown in figure 1 was performed, to check this hypothesis. The equations used for the analysis are described by Darling, et al. (1995), and are based on the method of Bloxidge, et al. (1988). The stiffness of the system due to the acoustic impedance as well as the acceleration of the mean flow through the flame and converging sections were included in the model. Ideal boundary conditions of a pressure antinode at the fuel-air mixture dump plane and a pressure node at the exit (where the flow exhausts into the spray chamber) were used. The mean heat release rate was assumed to take place uniformly in the volume between the dump plane and the end of the converging section. This analysis differs from the cited references in that, here, we are not looking for an unstable eigenvalue, but rather a response (measured at the transducer location) to a spectrally uniform (broadband) acoustic source located at the center of the heat release region.

The magnitude of the response function predicted by the analysis is shown in figure 3 for the same mean flow conditions as the sample spectrum given in figure 2 . The predicted peaks are primarily due to the resonances of the chamber, while the calculated anti-resonance, at just over $1000 \mathrm{~Hz}$, is due to the location of the transducer within the flame tube. The peaks of the computed response function are close to, but not exactly the same as, the peaks of the measured spectrum. The differences are probably due to the simplifying assumptions made in the model. For example, the exit plane is not a perfect pressure node, the fuel-air mixture entry plane is not infinitely stiff (some acoustic energy will be transmitted into the premixing zone), and the acoustic source is not at a single location but is distributed over the whole volume where the heat release occurs, and the noise source is not completely spectrally uniform. Nonetheless, even with these simplifications, the shape and approximate frequencies of the calculated response function are close to those of the measured spectrum. As a result, it is difficult to identify the peak frequency of the noise generated by the flame in figure 2 , since the generated sound is strongly filtered by the combustion chamber acoustics. The benefit of this filtering is that, if we know the acoustics of the combustor, we can predict the approximate frequencies of the broadband sound that would be observed.

It was stated above that the broadband power spectra are consistent at different operating conditions. This consistency is demonstrated in figure 4 , which shows the power density spectra for configuration 1 operating at a flame temperature of $1870 \mathrm{~K}$ and an equivalence ratio of 0.52 . Figure 4 shows the effect of variations in the mean pressure on the broadband combustor noise. The mean pressure in the combustor was changed from $10 \mathrm{~atm}$ to 13 atm, while holding constant the flame temperature, equivalence ratio and flow velocity. The 30 percent increase in mean pressure resulted in a 16 percent increase in the fluctuating pressure (integrated over all frequencies): from $1.92 \mathrm{kPa}(0.278 \mathrm{psi}) \mathrm{rms}$ to $2.24 \mathrm{kPa}$ $(0.325 \mathrm{psi}) \mathrm{rms}$. This increase was typical of the observed effect of mean pressure on the broadband noise.
Increasing the mean pressure increased the fluctuating pressure, but not by the same factor. Again, the general shape of the power spectral density curve remained approximately the same as for the previous example.

In addition to the mean pressure, the equivalence ratio and inlet air temperature affected the magnitude of the pressure fluctuations. Table II shows results for configuration 2 , and inlet temperatures of $730 \mathrm{~K}$ and $770 \mathrm{~K}$. The equivalence ratio was varied from 0.44 to 0.54 .

In general, noise level increased with mean pressure, but decreased with increases in both equivalence ratio and inlet temperature. The only exception in table II is for an inlet temperature of $730 \mathrm{~K}$ and an equivalence ratio of 0.44 - the fluctuating pressure increased slightly when the mean pressure was reduced from 12 to $10 \mathrm{~atm}$. The increase may have been caused by variations in the equivalence ratio. The trends given in table II were observed in the broadband noise for all four configurations.

\section{SHARP PEAK NOISE RESULTS}

In the previous section we examined combustion noise when the unsteady heat release rate was either not affected by the chamber acoustics or, at least, not in a way that excited a resonance that could be observed above the broadband noise. But this lack of excitation was not always the case. Particularly with configurations 3 and 4 , which had no pilot stage, acoustic resonances were often observed. The resonances were very sensitive to changes in the mean flow conditions, and the effects of these changes were not always consistent. For example, at low inlet temperatures (near $550 \mathrm{~K}$ ), increasing equivalence ratio increased a resonant peak, while at higher inlet temperatures (above $800 \mathrm{~K}$ ), increasing equivalence ratio decreased the resonant peak.

Changing the mean flow altered not only the amplitude of resonant peaks, but sometimes the general character of the noise. At a flame temperature of $1760 \mathrm{~K}$, an equivalence ratio of 0.44 , and a mean pressure of $9 \mathrm{~atm}$, configuration 4 experienced low frequency pulsing. Figure 5 shows the power spectral density for such a situation. The pulsing can also be seen in the time trace of the fluctuating pressure (figure 6). The frequency was low enough that visible light intensity from the flame could be visually observed to fluctuate. When the mean pressure was increased to $14 \mathrm{~atm}$, the low frequency pulsing disappeared; the low frequency peaks were several orders of magnitude smaller in the power density spectrum (figure 7) and the pulsing could not be observed visually through the quartz window. The overall shape of the spectrum returned to the broadband noise spectrum seen in earlier examples. Because the higher mean pressure did not produce the resonance, the total noise level decreased from 5.4 to $4.6 \mathrm{kPa}$. This trend is opposite to that observed for the broadband noise.

Figure 8 illustrates another resonance, in this case in configuration 3 . Here, again, the mean pressure was changed. It was increased from 7.5 to $10 \mathrm{~atm}$. The frequency of the largest peak remained the same, as one might expect, since the inlet temperature and equivalence ratio did not change. In this case, the total noise level increased from 4.03 to $5.80 \mathrm{kPa}$ (this increase is consistent with the trend for broadband noise). 
Meanwhile, the magnitude of the spectral peak increased more dramatically-from $1.09 \mathrm{kPa}^{2} / \mathrm{Hz}$ to $6.27 \mathrm{kPa}^{2} / \mathrm{Hz}$, a $7.6 \mathrm{~dB}$ increase in that tone. In addition, a harmonic of that tone that was not observed at $7.5 \mathrm{~atm}$ was seen at 10 atm. These results are typical of resonances seen in the combustor: the resonant tones were much more sensitive to changes in the mean flow conditions than was the broadband noise. The resonant peaks are caused by feedback between the fluctuating pressure and the unsteady heat release rate. This feedback is caused by interactions between the upstream and downstream regions of the combustor. The elucidation of the actual mechanisms of these interactions is the goal of ongoing investigations.

Occasionally, the resonant peaks dominated the combustor noise even more than in the previous example. Figures 9 and 10 show an example of such a case. Multiple narrow peaks and their harmonics can be seen in the spectrum (figure 10). In this case, the total pressure fluctuation (rms) was $32.3 \mathrm{kPa}$. The frequencies were too high to see any emitted light fluctuations visually through the quartz window; however, the magnitude of the fluctuations was much more severe than in the previous cases (see figures 5, 6, 9, and 10).

Often, resonances occurred near lean blow out. The pressure traces looked highly nonlinear, representing multiple modes and nonlinear interactions. This type of interaction is important, since many low emission combustor designs involve burning at fuel-lean conditions, to reduce $\mathrm{NO}_{\mathrm{x}}$ production. Figure 11 shows the temporal trace of the fluctuating pressure near lean blow out, when there was a very low frequency (about $8 \mathrm{~Hz}$ ) pulsing of the flame, again accompanied by visible pulsing of light in the combustor. This pulsing, which was very regular, appears to be associated with a bulk oscillation mode of the chamber. The mean pressures and temperatures, where this type of noise was observed, essentially corresponded to the lean blow out points of the combustor.

\section{CONCLUSIONS}

Dynamic pressure measurements were made in a premixed, liquid-fueled (JP-5) gas turbine combustor with four different configurations. The fluctuating pressure was measured at various flow conditions, mean pressures between $6 \mathrm{~atm}$ and $14 \mathrm{~atm}$, inlet temperatures between 550 and $850 \mathrm{~K}$, and equivalence ratios between 0.35 and 0.57 . In general, the broadband noise spectra were very similar from one condition to another and from configuration to configuration. The shape of the spectrum was apparently influenced by the acoustics of the combustion zone. The filtering of the broadband noise by the combustion chamber acoustics ensured the basic consistency in the broadband spectra. The trends in broadband noise seen at low mean pressures were also usually seen at high mean pressures, that is, the total sound level decreased with increasing equivalence ratio or inlet temperature. These results suggest that low pressure testing may be adequate to evaluate a combustor design change as to its effects on broadband noise. However, the frequencies obtained at low mean pressure will match those at high mean pressure only if the geometry and acoustic boundary conditions remain the same.

The configurations without a central pilot experienced higher broadband noise levels and were more susceptible to narrow peak resonances than the configurations with a central pilot. These differences were observed at both low and high mean pressures.

In contrast to the broadband noise, the sharp peaks were very sensitive to the mean flow conditions. Also, the effects were not always consistent; at some conditions, increasing the equivalence ratio made the sharp peaks grow, while at other conditions, increasing the equivalence ratio made the sharp peaks shrink. Although it was not easy to predict when resonances would occur, they were reproducible. Acoustic coupling between different sections of the test rig may be a factor in the sharp-peaked oscillations.

Our results suggest that a series of low pressure tests could be used to examine if one combustor design is generally more susceptible to instabilities than another. However, high pressure tests, with realistic acoustic boundaries, are apparently still necessary to know exactly when a particular gas turbine combustor will experience sharp resonances.

The noise that is observed very close to lean blow out is affected by the chamber acoustics, in that the chamber acoustics apparently maintain the fluctuations at a uniform frequency. However, the actual conditions when this noise was experienced simply followed the lean blow out limit as it varied with mean temperature and pressure.

\section{ACKNOWLEDGMENT}

This work was performed as part of the High Speed Research Program at the NASA Lewis Research Center.

\section{REFERENCES}

Bloxidge, G.J., Dowling, A.P., Hooper, N., Langhorne, P.J., "Active Control of Reheat Buzz," AIAA J., Vol. 26, 1988, pp. 783-790.

Darling, D.D., Radhakrishnan, K., Oyediran, A., Cowan, E., "Combustion-Acoustic Stability Analysis for Premixed Gas Turbine Combustors," AIAA 95-2470, NASA TM-107024, 1995.

Heidmann, M.F., Groeneweg, J.F., "Analysis of the Dynamic Response of Liquid Jet Atomization to Acoustic Oscillations," NASA TN D-5339, 1969.

Heidmann, M.F., Weiber, P.R., "Analysis of Frequency Response Characteristics of Propellant Vaporization," NASA TN D-3749, 1966.

Keller, J.J., "Thermoacoustic Oscillations in Combustion Chambers of Gas Turbines," AIAA J., Vol. 33, No. 12, 1995, pp. 2280-2287. 
Keller, J.O., Vaneveld, L., Korschelt, D., Hubbard, G..L., Ghoniem, A.F., Daily, J.W., Oppenheim, A.K., "Mechanism of Instabilities in Turbulent Combustion Leading to Flashback," AIAA J., Vol. 20, No. 2, 1982, pp. 254-262.

Mahan, J.R., "A Critical Review of Noise Production Models for Turbulent, Gas-Fueled Burners," NASA CR-3803, 1984.

Neumeier, Y., Nabi, A., Zinn, B.T., "Investigation of the Open Loop Performance of an Active Control System Utilizing a Fuel Injector Actuator," AIAA 96-2757, 1996.
Putnam, A.A., Belles, F.E., Kentfield, J.A.C., "Pulse Combustion," Prog. Energy Combust. Sci., Vol. 12, 1986, pp. 43-79.

Richards, G.A., Yip, M.J., Robey, E., Cowell, L., Rawlins, D., "Combustion Oscillation Control by Cyclic Fuel Injection," ASME 95-GT-224, 1995.

Strahle, W.C., "Some Results in Combustion Generated Noise," J. of Sound and Vibration, Vol. 23, No. 1, 1972, pp. 113-125.

TABLE I.-COMBUSTOR CONFIGURATIONS

\begin{tabular}{|c|c|c|c|}
\hline Configuration & Stage A & Stage B & Stage C \\
\hline 1 & Premixed 1 & Pilot 1 & Premixed 1 \\
2 & Premixed 1 & Pilot 2 & Premixed 1 \\
3 & Premixed 1 & Premixed 2 & Premixed 1 \\
4 & Premixed 1 & Premixed 1 & Premixed 1 \\
\hline
\end{tabular}

TABLE II.-PRESSURE FLUCTUATION (rms), IN kPa FOR CONFIGURATON 2

(a) $T_{\text {in }}=730 \mathrm{~K}$

\begin{tabular}{|c|c|c|c|c|}
\hline$\Phi$ & $p=14 \mathrm{~atm}$ & $p=12 \mathrm{~atm}$ & $p=10 \mathrm{~atm}$ & $p=9 \mathrm{~atm}$ \\
\hline 0.44 & 2.67 & 2.32 & 2.34 & 2.31 \\
0.49 & 2.40 & 2.06 & 1.98 & 1.70 \\
0.52 & 2.24 & 2.01 & 1.92 & 1.59 \\
\hline
\end{tabular}

(b) $T_{\mathrm{n}}=770 \mathrm{~K}$

\begin{tabular}{|c|c|c|c|}
\hline$\Phi$ & $p=10 \mathrm{~atm}$ & $p=9 \mathrm{~atm}$ & $p=8 \mathrm{~atm}$ \\
\hline 0.44 & 1.82 & 1.69 & 1.51 \\
0.49 & 1.76 & 1.55 & 1.30 \\
0.50 & 1.75 & 1.40 & 1.24 \\
0.54 & & & \\
\hline
\end{tabular}




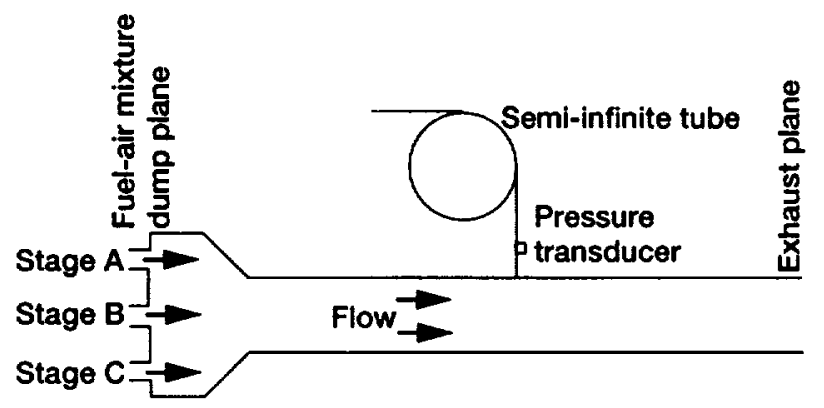

Figure 1.-Experimental setup (not to scale).

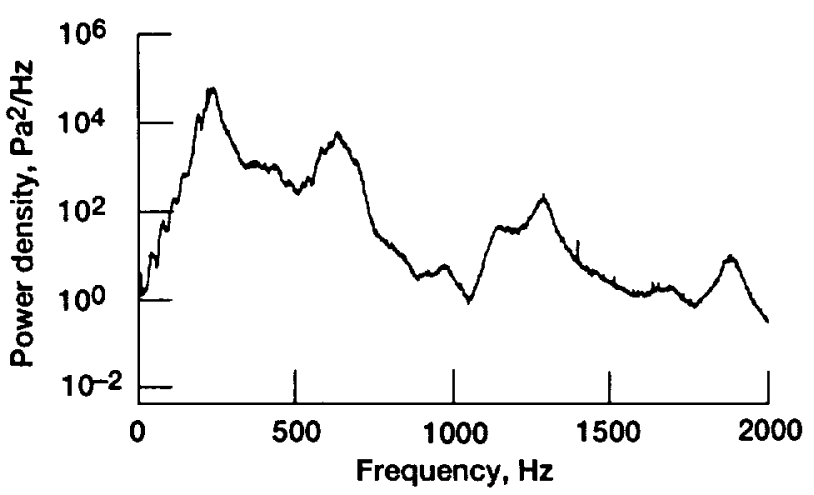

Figure 2.-Power spectral density for configuration 3 at flame temperature of $1840 \mathrm{~K}$, equivalence ratio of 0.547 , and mean pressure of $10 \mathrm{~atm}$.

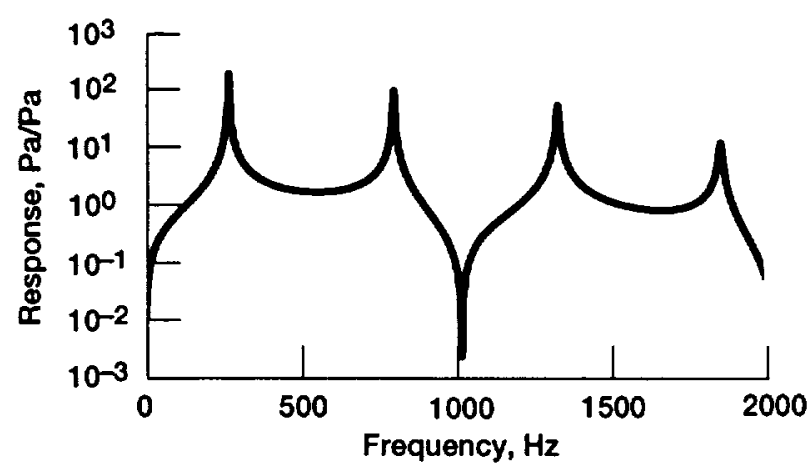

Figure 3.-Predicted magnitude of the response function of spectrally uniform acoustic source located at the center of the heat release zone. The response is measured at the transducer location. The mean flow conditions match those of figure 2: flame temperature of $1840 \mathrm{~K}$, equivalence ratio of 0.547 , and mean pressure of $10 \mathrm{~atm}$.

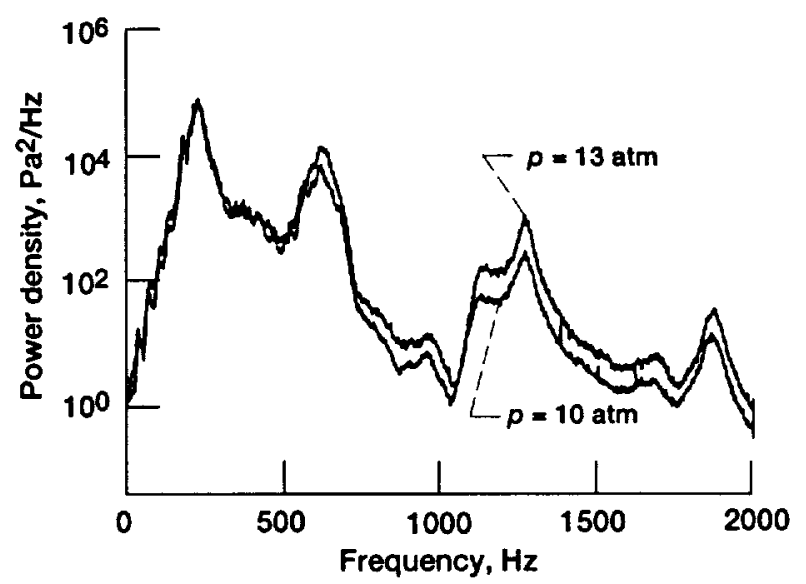

Figure 4.-Power spectral density of broadband noise for configuration 1 at mean pressures of 10 and $13 \mathrm{~atm}$. The flame temperature was $1870 \mathrm{~K}$ and the equivalence ratio 0.547 .

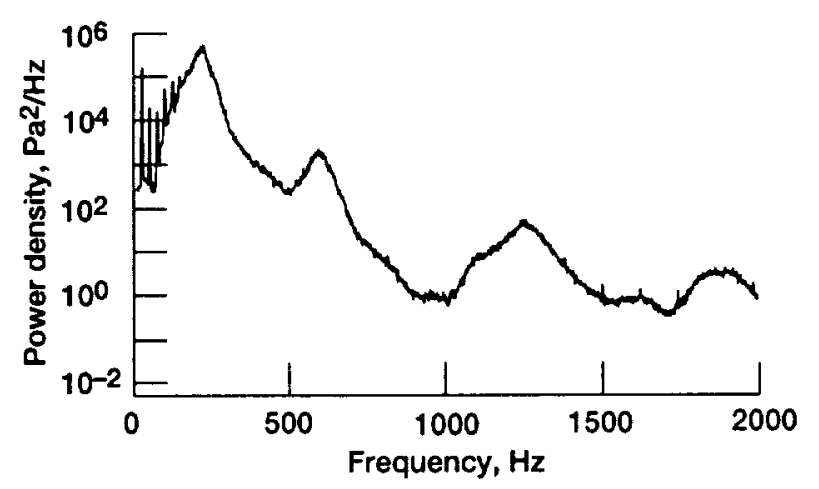

Figure 5.-Power spectral density showing low frequency pulsing when configuration 4 was operated at flame temperature of $1760 \mathrm{~K}$, equivalence ratio of 0.469 , and mean pressure of $9 \mathrm{~atm}$.

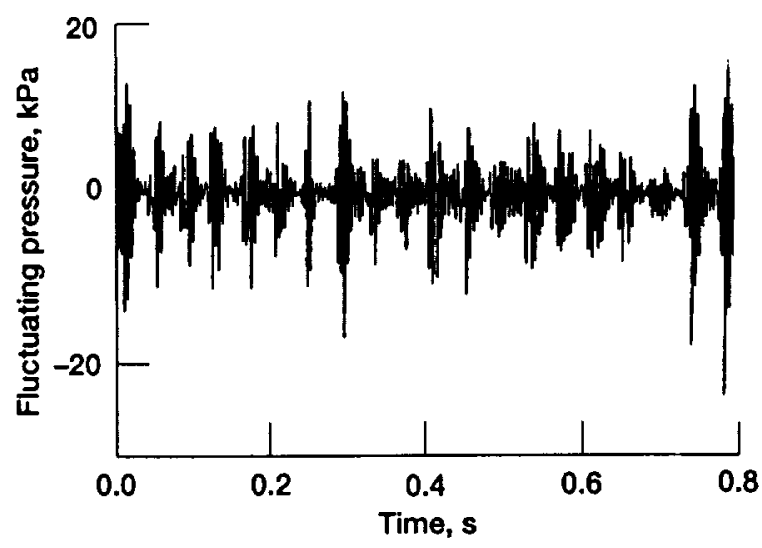

Figure 6.-Pressure time trace showing low frequency pulsing when configuration 4 was operated at flame temperature of $1760 \mathrm{~K}$, equivalence ratio of 0.469 , and mean pressure of $9 \mathrm{~atm}$. 


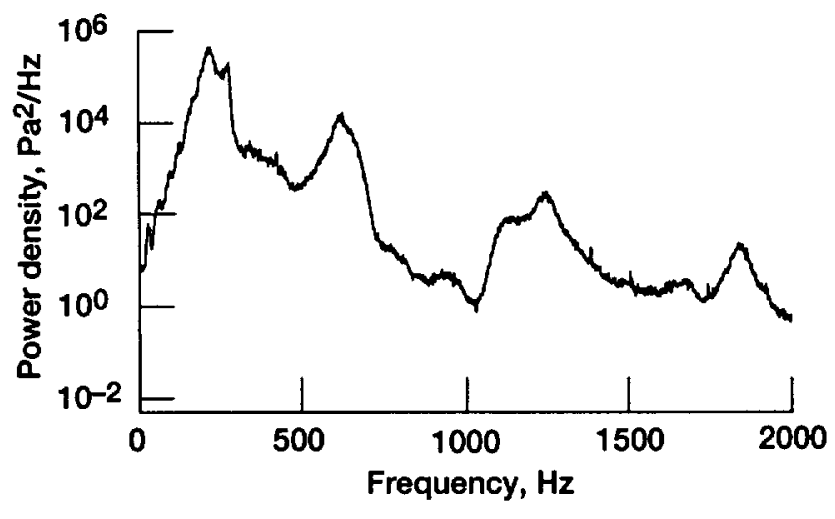

Figure 7.-Power spectral density showing that the low frequency peaks are several orders of magnitude smaller when the mean pressure was increased to 14 atm (configuration 4). The flame temperature was $1760 \mathrm{~K}$ and the equivalence ratio 0.469 .

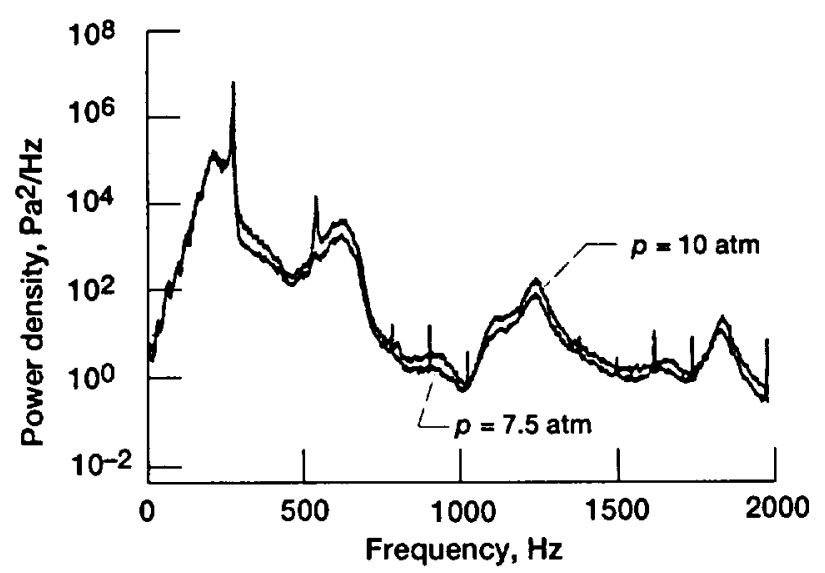

Figure 8.-Power spectral density for configuration 3 at mean pressures of 7.5 and $10 \mathrm{~atm}$. The flame temperature was $1760 \mathrm{~K}$ and the equivalence ratio 0.469 .

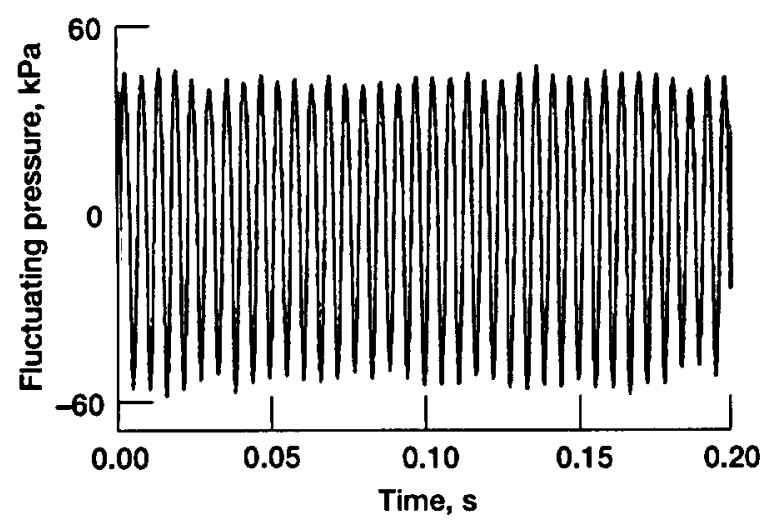

Figure 9.-Time trace of fluctuating pressure when the noise was dominated by sharp resonant peaks. The flame temperature was $1860 \mathrm{~K}$ and the equivalence ratio 0.609 .

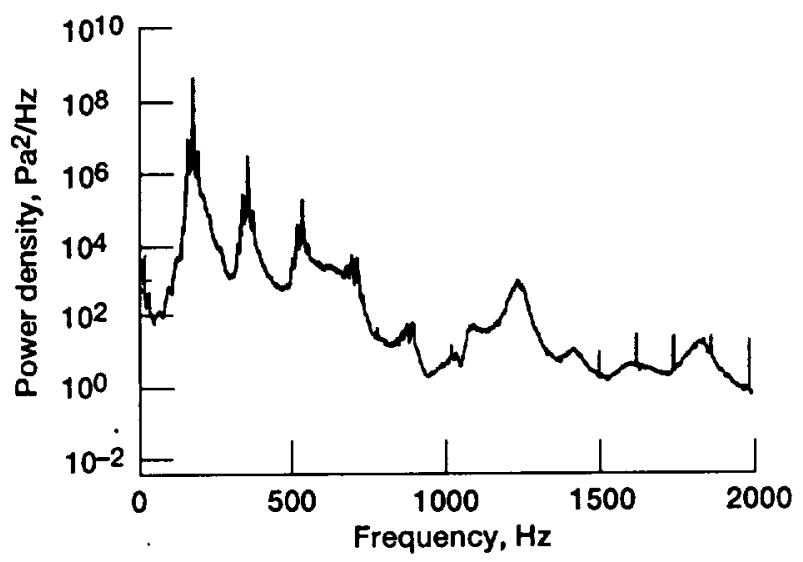

Figure 10.-Power spectral density when the oscillating pressure was dominated by sharp peaks. The flame temperature was $1860 \mathrm{~K}$ and the equivalence ratio 0.609 .

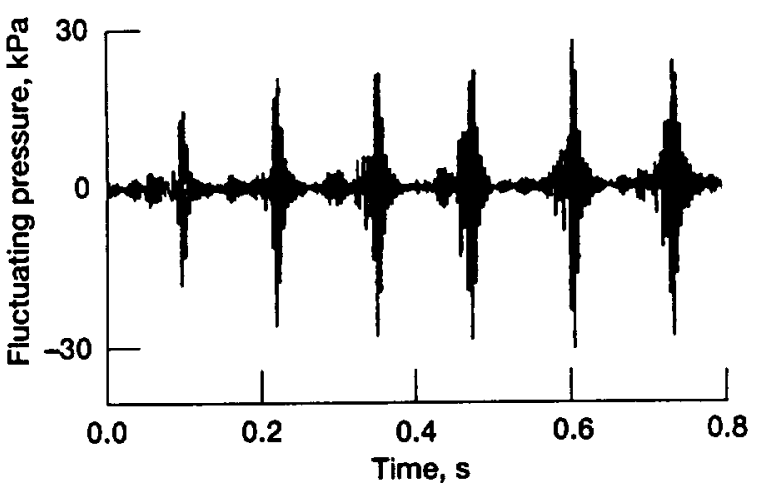

Figure 11.-Time trace of fluctuating pressure when the combustor was operating near its lean blow out limit. 
Public reporting burden for this collection of information is estimated to average 1 hour per response, Including the time for reviewing instructions, searching existing data sources, gathering and maintaining the data needed, and completing and reviewing the collectlon of information. Send comments regarding this burden estimale or any other aspect of this collection of Informatlon, including suggestions for reducing this burden, to Washington Headquarters Services. Directorate for Information Operations and Reports. 1215 Jefferson Davis Highway. Suite 1204, Artington, VA 22202-4302, and to the Office of Menagement and Budget. Papenwork Feduction Project (0704-0188), Washington, DC 20503.

\begin{tabular}{|l|l|l} 
1. AGENCY USE ONLY (Leave blank) & $\begin{array}{c}\text { 2. REPORT DATE } \\
\text { June } 1997\end{array}$ & $\begin{array}{r}\text { 3. REPORT TYPE AND DATES COVERED } \\
\text { Technical Memorandum }\end{array}$ \\
\hline
\end{tabular}

4. TITLE AND SUBTITLE

5. FUNDING NUMBERS

Combustion Noise at Elevated Pressures in a Liquid-Fueled

Premixed Combustor

6. AUTHOR(S)

WU-537-02-21

Douglas Darling, Krishnan Radhakrishnan, and Ayo Oyediran

7. PERFORMING ORGANIZATION NAME(S) AND ADDRESS(ES)

8. PERFORMING ORGANIZATION

REPORT NUMBER

National Aeronautics and Space Administration

Lewis Research Center

Cleveland, Ohio 44135-3191

E-10773

9. SPONSORING/MONITORING AGENCY NAME(S) AND ADDRESS(ES)

National Aeronautics and Space Administration

Washington, DC 20546-0001

10. SPONSORINGMONITORING

AGENCY REPOAT NUMBER

NASA TM- 107481

ASME-97-GT-308

\section{SUPPLEMENTARY NOTES}

Prepared for the Turbo-Expo 97 sponsored by the International Gas Turbine Institute of the American Society of Mechanical Engineers, Orlando, Florida, June 2-5, 1997. Douglas Darling, currently with Westinghouse Electric Corporation, Orlando, Florida; Krishnan Radhakrishnan, NYMA, Inc., 2001 Aerospace Parkway, Brook Park, Ohio 44142 (work funded by NASA Contract NAS3-27186); Ayo Oyediran, AYT Corporation, Brook Park, Ohio 44142 (work funded by NASA Contract NAS3-27571). Responsible person, Krishnan Radhakrishnan, organization code 5830, (216) 977-1155.

12a. DISTRIBUTION/AVAILABILITY STATEMENT

12b. DISTRIBUTION CODE

Unclassified - Unlimited

Subject Categories 07, 64, and 34

This publication is available from the NASA Center for AeroSpace Information, (301) 621-0390.

\section{ABSTRACT (Maximum 200 words)}

Noise generated in gas turbine combustors can exist in several forms-broadband noise, sharp resonant peaks, and regular or intermittent nonlinear pulsing. In the present study, dynamic pressure measurements were made in several JP-5-fueled combustor configurations, at various mean pressures and temperatures. The fluctuating pressure was measured at mean pressures from 6 to 14 atm and inlet temperatures from $550 \mathrm{~K}$ to $850 \mathrm{~K}$. The goal of the present work was to study the effect of changes in mean flow conditions on combustor noise: both broadband noise and sharp tones were considered. In general, the shape of the broadband noise spectrum was consistent from one configuration to another. The shape of the spectrum was influenced by the acoustic filtering of the combustion zone. This filtering ensured the basic consistency of the spectra. In general, the trends in broadband noise observed at low mean pressures were also seen at high mean pressures; that is, the total sound level decreased with both increasing equivalence ratio and increasing inlet temperature. The combustor configurations without a central pilot experienced higher broadband noise levels and were more susceptible to narrow peak resonances than configurations with a central pilot. The sharp peaks were more sensitive to the mean flow than was the broadband noise, and the effects were not always the same. In some situations, increasing the equivalence ratio made the sharp peaks grow, while at other conditions, increasing the equivalence ratio made the sharp peaks shrink. Thus, it was difficult to predict when resonances would occur; however, they were reproducible. Acoustic coupling between the upstream and downstream regions of the combustor may play a role in the sharp-peaked oscillations. Noise was also observed near lean blow out. As with other types of noise, lean blow out noise was affected by the combustion chamber acoustics, which apparently maintains the fluctuations at a uniform frequency. However, the actual conditions when this type of noise was experienced appeared to simply follow the lean blow out limit as it varied with mean temperature and pressure.

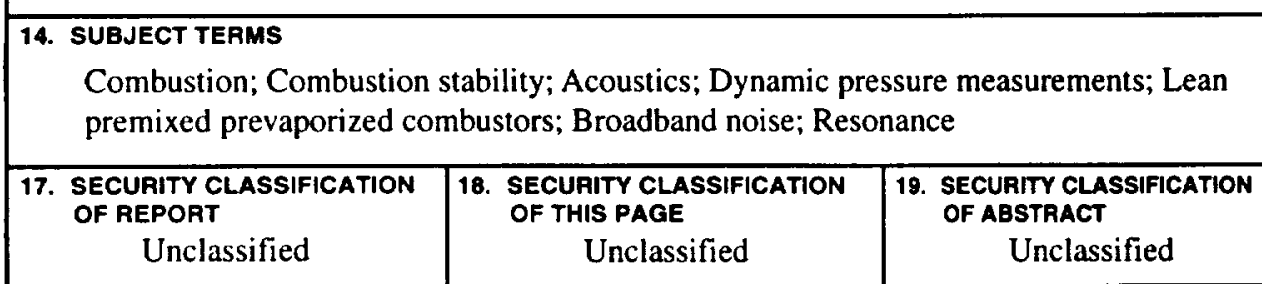

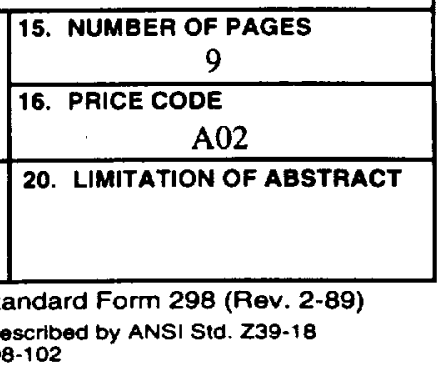

